OPEN ACCESS

Edited by:

Volker Eulenburg,

Universitätsklinikum Leipzig, Germany

Reviewed by:

Joshua Singer,

University of Maryland, College Park,

United States

Bela Volgyi,

University of Pécs, Hungary

Sammy Chi Sam Lee,

University of Sydney, Australia

*Correspondence:

Karin Dedek

karin.dedek@uni-oldenburg.de

Received: 27 December 2018

Accepted: 03 April 2019

Published: 23 April 2019

Citation:

Yadav SC, Tetenborg S and Dedek K (2019) Gap Junctions in A8 Amacrine

Cells Are Made of Connexin36 but Are Differently Regulated Than Gap

Junctions in All Amacrine Cells.

Front. Mol. Neurosci. 12:99.

doi: 10.3389/fnmol.2019.00099

\section{Gap Junctions in A8 Amacrine Cells Are Made of Connexin36 but Are Differently Regulated Than Gap Junctions in All Amacrine Cells}

\author{
Shubhash C. Yadav ${ }^{1}$, Stephan Tetenborg ${ }^{1}$ and Karin Dedek ${ }^{1,2 *}$ \\ ${ }^{1}$ Animal Navigation/Neurosensorics, Institute for Biology and Environmental Sciences, University of Oldenburg, Oldenburg, \\ Germany, ${ }^{2}$ Research Center Neurosensory Science, University of Oldenburg, Oldenburg, Germany
}

In the mammalian retina, amacrine cells represent the most diverse cell class and are involved in the spatio-temporal processing of visual signals in the inner plexiform layer. They are connected to bipolar, other amacrine and ganglion cells, forming complex networks via electrical and chemical synapses. The small-field A8 amacrine cell was shown to receive non-selective glutamatergic input from OFF and ON cone bipolar cells at its bistratified dendrites in sublamina 1 and 4 of the inner plexiform layer. Interestingly, it was also shown to form electrical synapses with ON cone bipolar cells, thus resembling the rod pathway-specific All amacrine cell. In contrast to the All cell, however, the electrical synapses of A8 cells are poorly understood. Therefore, we made use of the ler5-GFP mouse line, in which $A 8$ cells are labeled by GFP, to study the gap junction composition and frequency in A8 cells. We found that A8 cells form $<20$ gap junctions per cell and these gap junctions consist of connexin36. Connexin36 is present at both OFF and ON dendrites of A8 cells, preferentially connecting A8 cells to type 1 OFF and type 6 and 7 ON bipolar cells and presumably other amacrine cells. Additionally, we show that the OFF dendrites of A8 cells co-stratify with the processes of dopaminergic amacrine cells from which they may receive GABAergic input via $G_{A B} A_{A}$ receptor subunit $\alpha 3$. As we found $A 8$ cells to express dopamine receptor $D_{1}$ (but not $D_{2}$ ), we also tested whether A8 cell coupling is modulated by $D_{1}$ receptor agonists and antagonists as was shown for the coupling of All cells. However, this was not the case. In summary, our data suggests that A8 coupling is differently regulated than All cells and may even be independent of ambient light levels and serve signal facilitation rather than providing a separate neuronal pathway.

Keywords: amacrine cell, bipolar cell, gap junction, electrical synapse, connexin36, retina, dopamine

\section{INTRODUCTION}

In the inner plexiform layer (IPL) of the mouse retina, almost 100 different neurons (bipolar, amacrine and ganglion cells) are interconnected in neuronal pathways. Amacrine cells probably represent the most numerous class comprising more than 40 different cell types (Helmstaedter et al., 2013), each with unique properties, such as dendritic pattern, synaptic partners, and 
consequently physiological function. Amacrine cells are commonly divided according to their dendritic tree size into small-field and wide-field amacrine cells (Kolb et al., 1981). In the mammalian retina, this subdivision is also reflected in the neurotransmitter used by the cells: small-field cells are glycinergic (Menger et al., 1998), whereas wide-field cells are GABAergic (Chen et al., 2011). In the following, we will focus on small-field amacrine cells whose dendrites typically extend $<200 \mu \mathrm{m}$ and span several sublaminae in the IPL, thereby often crossing the OFF-ON boundary between sublamina 2 and 3 (Werblin, 2011).

Among the small-field amacrine cells, the bistratified AII amacrine cell is the best studied, revealing a highly complex synaptic network (Tsukamoto and Omi, 2013, 2017; Marc et al., 2014). This synaptic network comprises not only glycinergic synapses to OFF bipolar cells and-to a smaller degree-OFF ganglion cells, but also two distinct gap junctional networks, one among AII cells (homocellular coupling) and one between AII and ON cone bipolar cells (heterocellular coupling). AII amacrine cells and their gap junction circuitry have been extensively studied, highlighting the molecular composition (Feigenspan et al., 2001; Maxeiner et al., 2005; Meyer et al., 2016), assembly (Meyer et al., 2014), and remarkable plasticity of AII gap junctions (Mills and Massey, 1995; Bloomfield and Völgyi, 2004; Kothmann et al., 2009). Moreover, AII cells are essential elements of the primary rod pathway (Güldenagel et al., 2001; Deans et al., 2002) in that they collect scotopic signals from rod bipolar cells and transmit them via gap junctions to ON cone bipolar cells.

Due to the great amacrine cell diversity, it seems likely that other amacrine cells may also form electrical synapses (gap junctions) with bipolar cells, thereby potentially impacting bipolar cell signaling. Recently, we described such an amacrine cell in the mouse retina, the A8 amacrine cell (Lee et al., 2015). It shares interesting features with AII cells because it not only forms gap junctions with $\mathrm{ON}$ cone bipolar cells and potentially amacrine cells, but also represents a glycinergic small-field amacrine cell with bistratified morphology: OFF dendrites stratify in sublamina 1 of the IPL and ON dendrites in sublamina 4 (Figure 1). A8 cells were shown to receive glutamatergic input from OFF and ON cone bipolar cells and provide glycinergic inhibition to OFF cone bipolar cells and $\mathrm{ON}$ $\alpha$ ganglion cells (Lee et al., 2015). However, electrical synapses of A8 cells have not been studied in detail so far. Therefore, we used a combination of intracellular dye/tracer injections, pharmacology and immunohistochemical labeling to determine the gap junction protein (connexin subunit) expressed by A8 cells and the potential coupling partners and also to discern whether A8 gap junctions are modulated by dopamine. Here, we provide evidence that the electrical coupling of A8 amacrine cells is much weaker than that of AII amacrine cells, but involves the same gap junction protein, connexin36 (Cx36). However, whereas AII coupling is plastic and modulated by dopamine (Kothmann et al., 2009) in the mouse retina, A8 coupling is not affected by activating or blocking $\mathrm{D}_{1}$ dopamine receptors. Furthermore, our data suggests that A8 cells are coupled to type 6 and $7 \mathrm{ON}$ bipolar cells, which also represent the major coupling partners of AII amacrine cells (Tsukamoto and Omi, 2017). Interestingly,
A8 cells are coupled to OFF bipolar cells as well. Taken together, our data provides evidence that electrical coupling in the inner plexiform layer can differ considerably among different cell types, even if the cells couple to the same synaptic partners.

\section{MATERIALS AND METHODS}

\section{Animal and Tissue Preparation}

All procedures and experiments conducted in this study complied with the guidelines of the European Communities Council Directive (86/609/EEC) and the laws of the Federal Government of Germany (Tierschutzgesetz; BGBl. I S. 1206, 1313 and BGBl. I S. 1934) for experimental animals and were approved by the local animal care committee (Niedersaechsisches Landesamt fuer Verbraucherschutz und Lebensmittelsicherheit).

In this study, C57BL/6J and Ier5-EGFP mice (Siegert et al., 2009; Lee et al., 2015) were used. Mice picked for the experiments were typically 2-9 months old and of either sex.

For AII and A8 cell injections in retinal whole-mounts, mice were deeply anesthetized with $\mathrm{CO}_{2}$ and euthanized by cervical dislocation. Thereafter, eyes were enucleated; subsequently, cornea, lens and vitreous body were removed in extracellular solution (in mM: $110 \mathrm{NaCl}, 2.5 \mathrm{KCl}, 1 \mathrm{CaCl}_{2}, 1.6 \mathrm{MgCl}_{2}, 10$ glucose, $22 \mathrm{NaHCO}_{3}$, adjusted to $\mathrm{pH} 7.4$ by gassing with $95 \%$ $\mathrm{O}_{2}$ and $5 \% \mathrm{CO}_{2}$ ) at room temperature. Retinas were carefully extracted from the eyecups and bisected with a clean razor blade. Any residual vitreous body was thoroughly removed with a pair of blunt tweezers. Retinal pieces were then mounted on a black filter paper ganglion cell side up (Meyer et al., 2018). To visualize AII amacrine cells, the retinal piece was incubated in $0.0001 \%$ DAPI solution for 30-45 min prior to the injection.

For slice immunohistochemistry, the cornea was cut along the ora serrata, leaving the posterior eyecup which was fixed in $2 \%$ paraformaldehyde (PFA) in $0.1 \mathrm{M}$ phosphate buffer (PB) for $3 \times 10 \mathrm{~min}$, washed in $\mathrm{PB}$ and immersed in $30 \%$ sucrose in PB overnight.

\section{Intracellular Dye and/or Neurobiotin Injections}

Intracellular injections were performed as described previously (Tetenborg et al., 2017). In short, thin-walled borosilicate glass electrodes with filament were pulled with a Sutter P-97 puller (Sutter, Novato, CA, USA), resulting in electrodes with a resistance between 100 and $150 \mathrm{M} \Omega$. The electrode tips were then filled with $2 \mu \mathrm{l}$ of $5 \mathrm{mM}$ Alexa Fluor 488/568 potassium hydrazide and $4 \%$ Neurobiotin (w/v), which was diluted in $0.2 \mathrm{M}$ $\mathrm{KCl}$. Thereafter, the electrodes were backfilled with $8 \mu \mathrm{l}$ of $0.2 \mathrm{M}$ $\mathrm{KCl}$. The dye was iontophoresed with $-0.5 \mathrm{nA}$ square pulses $(500 \mathrm{~ms}$ at $1 \mathrm{~Hz}$ ) for $5 \mathrm{~min}$.

In case of tracer coupling experiments, retinas were either pre-treated with $10 \mu \mathrm{M} D_{1}$ receptor antagonist Schering23390 (Sch23390), $10 \mu \mathrm{M} \mathrm{D}_{1}$ receptor agonist SKF38393 (SKF) or with extracellular solution (control) for $15 \mathrm{~min}$ (Hampson et al., 1992). The retina was constantly superfused with either Sch23390, SKF or control solution until fixation. The Alexa dye was iontophoresed with $-0.5 \mathrm{nA}$ pulses for 1 min to judge the proper impalement of the amacrine cell. Subsequently, the current was 

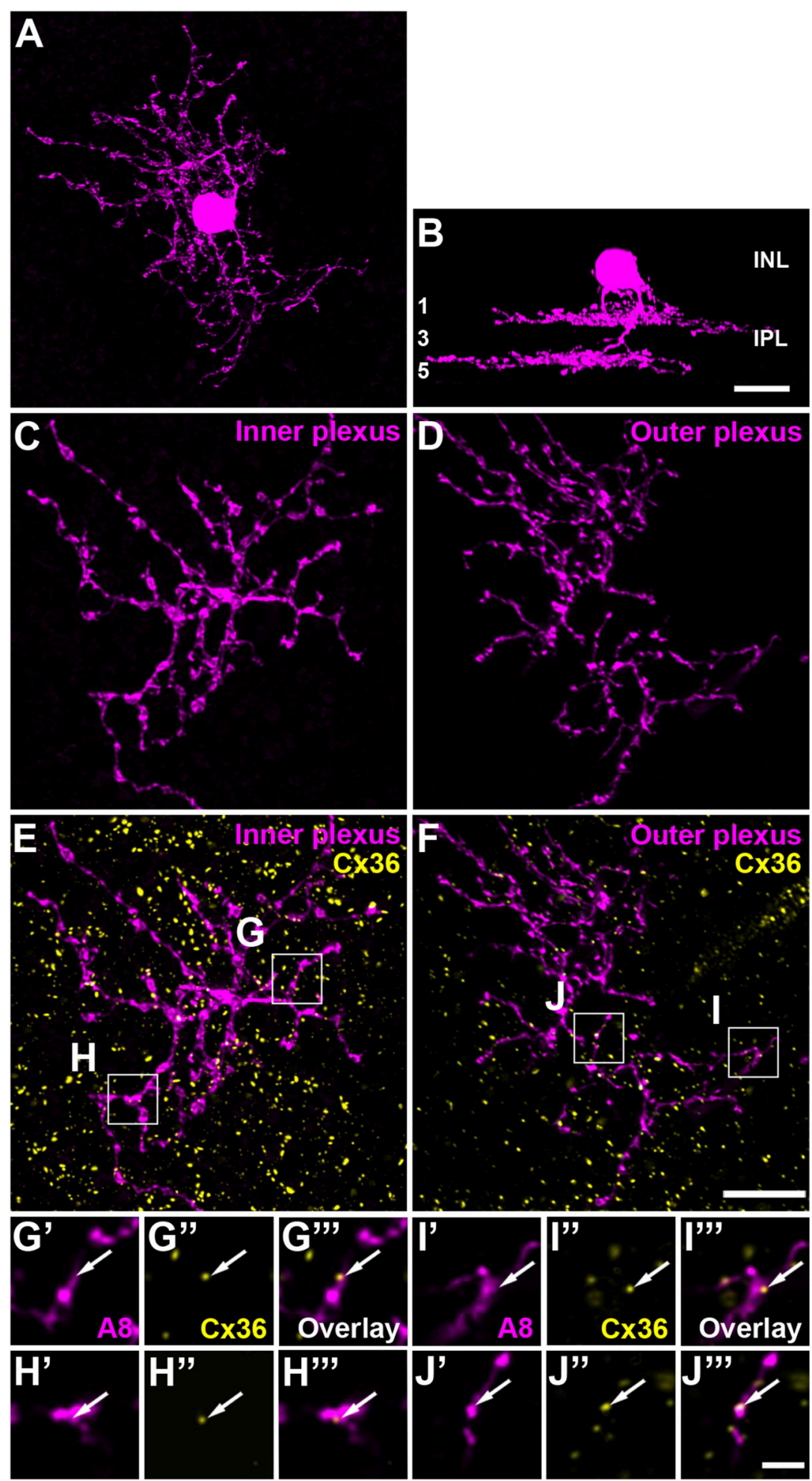

FIGURE 1 | A8 cell expressed connexin36 (Cx36) at their inner and outer plexus, in the ON and OFF sublamina of the inner plexiform layer (IPL), respectively.

(A) Maximum projection of an Alexa-568-injected A8 cell. (B) Same cell as in (A), XZ-rotation of a confocal stack shows the typical bistratified morphology of the A8 cell. (C,D) Maximum projection of inner (C) and outer dendrites (D) of the injected A8 cell. (E,F) Maximum projection of the overlay of Cx36 with inner $(\mathbf{E})$ and outer

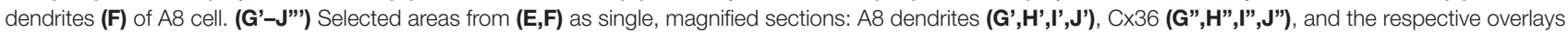
(G','H"','”,'J"'). Arrows denote colocalization of Cx36 with A8 cell dendrites. Scale bar: (A-F), $10 \mu \mathrm{m}$; (G'-J"'), $2 \mu \mathrm{m}$. 
reversed in order to inject Neurobiotin for $5 \mathrm{~min}$. In order to minimize bias, at least a couple of cells were injected in both control and treated condition on a single day. In all cases, the dye or tracer was allowed to diffuse for $15 \mathrm{~min}$ ahead of fixation. Since only light-adapted retinas were used for injections under epifluorescence $\left(1.6 \mathrm{~W} / \mathrm{m}^{2}\right)$ and in the presence of dim room light $\left(5.5 \mathrm{~mW} / \mathrm{m}^{2}\right)$, results represent photopic conditions.

\section{Immunohistochemistry}

The dye- or Neurobiotin-injected whole-mount retinas were fixed with $4 \%$ PFA in $0.1 \mathrm{M} \mathrm{PB}$. Subsequently, the retinas were thoroughly washed $3 \times 10 \mathrm{~min}$ with $\mathrm{PB}$. For coupling studies, the retina was then incubated in Alexa Fluor 546/647-conjugated streptavidin (1:250) overnight at room temperature to visualize the Neurobiotin. For immunostainings, retinas were incubated with primary antibodies (in PB containing $5 \% \mathrm{NDS}, 0.05 \% \mathrm{NaN}_{3}$, $0.3 \%$ Triton-X) for $2-3$ days at room temperature (Table 1 ). Thereafter, the samples were extensively washed and incubated with the respective secondary antibodies, conjugated to Alexa 488, Alexa 568, or Alexa 647 (1:250, Fisher Scientific), for 1 day at room temperature. The retinas were again washed thoroughly and mounted in Vectashield.

For immunostainings of vertical retina slices, the cryoprotected tissue was sliced into $20 \mu \mathrm{m}$ sections. After blocking with $10 \%$ normal donkey serum (NDS) in TBS-Tx (TRIS-buffered saline with $0.3 \%$ TritonX-100, $\mathrm{pH} 7.6$ ), the sample was incubated with primary antibodies (Table 1) diluted in blocking solution overnight (at $4^{\circ} \mathrm{C}$ ). Secondary antibodies were conjugated to Alexa 488, Alexa 568 or Alexa 647 (1:500, Fisher Scientific) and were applied for $2 \mathrm{~h}$ at room temperature. Washing steps were performed exclusively with TBS-Tx.

\section{Image Acquisition and Analysis}

Images were obtained with a confocal laser scanning microscope (Leica TCS SP8). Z-stack images of retinal whole-mounts and cryosections were acquired with HC PL APO CS2 40x/1.3 and HC PL APO CS2 63x/1.4 oil objectives, respectively. For colocalization analyses, the pixel size was kept constant (47 $\times 47 \mathrm{~nm}$ ) throughout a series of experiments and the stacks were taken at a $\mathrm{z}$-distance of maximally $0.2 \mu \mathrm{m}$ between optical sections. Notably, the OFF and ON dendrites of A8 cell were scanned separately to ensure that the entire dendritic field was captured without having to compromise with resolution. To analyze A8 and AII cell coupling, the stacks were acquired at a $\mathrm{z}$ distance of $0.3-0.5 \mu \mathrm{m}$. It should be noted that sometimes scans with higher gain were necessary in order to not miss the weakly streptavidin-stained cells in coupling experiments.

Except for the coupling data, each acquired stack was deconvolved. This was achieved by using a theoretical point spread function in Huygens Essential deconvolution software. The deconvolved data thus obtained was subsequently processed in Fiji (https://fiji.sc/, Schindelin et al., 2012) as described before (Tetenborg et al., 2017). Stacks of the injected cells were 3Dprojected to visualize the stratification pattern in the IPL. A8 cells showed the typical bistratified morphology (Figure 1) (Kolb et al., 1981; Lee et al., 2015).
Colocalization between two channels was crudely estimated by the colocalization highlighter plugin and global thresholds (IsoData, Otsu, and Moments) in Fiji. This resulted in 8-bit and RGB images, displaying colocalized puncta of the twotested channels, which were maximum-projected. Thereafter, the merged stack was $3 \mathrm{D}$-projected and rotated $360^{\circ}$ in $\mathrm{x}$ - and $\mathrm{y}$-axis at $5^{\circ}$ steps (Supplementary Movie). Simultaneously, the above mentioned colocalized puncta were tested for their association at each step. If they dissociated at any step, the colocalization was discarded. Else, the colocalization was declared to be true. As colocalization was exclusively quantified for deconvolved images, it might be slightly underestimated. For multiple channels, the colocalization analysis was conducted sequentially. Images that represent this analysis have been adjusted for brightness and contrast in Adobe Photoshop CS5 for presentation purposes.

It should be noted that the colocalization analysis was performed solely on the retinal whole-mount data. Retinal slices were only used to confirm the presence of colocalization observed in the whole-mount data. Accordingly, we did not quantify the colocalization observed in the retinal slices. We rather judged the colocalization based on the normalized pixel intensity profile of the channels of interest (Kántor et al., 2017). Also, the number of coupled cells were counted manually. Occasionally, we had to count cells at slightly higher gamma values in order to not miss weakly coupled or stained cells.

\section{Statistical Analysis}

Unless stated otherwise, data is presented as mean $\pm \mathrm{sd}$ (standard deviation). Data on A8 and AII coupling was not normally distributed. Therefore, the Wilcoxon rank sum test was used in Matlab R2016a to test for significant differences between control, Sch23390 and SKF at a significance level of 5\%.

\section{RESULTS}

\section{Composition of Gap Junctions in A8 Amacrine Cells}

The glycinergic, bistratified A8 amacrine cell (Figures 1A,B) was shown to couple to bipolar cells (mouse: Lee et al., 2015) and bipolar and amacrine cells (cat: Kolb and Nelson, 1996). However, the gap junction protein that mediates this coupling has not been identified so far. To answer this question, we dyeinjected individual A8 amacrine cells in the Ier5-GFP mouse line and labeled them for Cx36 (Figures 1E-J"') and Cx45 (Figure S1), which represent the two most abundant connexins in the IPL of the mouse retina (Feigenspan et al., 2001; Dedek et al., 2006; Li et al., 2008). Injected A8 cells expressed $7.5 \pm$ 1.8 Cx36-positive puncta on ON (Figures 1E,G-H"') and 9.9 \pm 2.1 Cx36-positive puncta on OFF dendrites (Figures 1F,I-J"'; Table 2; $\mathrm{N}=21$ cells, from 15 mice). The number of colocalized puncta was rather low when compared to AII amacrine cells which were shown to express $\sim 145 \mathrm{Cx} 36$-positive puncta on their arboreal (ON) dendrites (Meyer et al., 2014). Next, we tested for Cx45 expression; however, colocalization was rare with only 2.2 $\pm 0.4 \mathrm{Cx} 45$-positive puncta on $\mathrm{A} 8 \mathrm{ON}$ dendrites and $4.6 \pm 1.1$ Cx45-positive puncta on A8 OFF dendrites $(N=5$ cells, from 5 
TABLE 1 | List of primary antibodies used in this study.

\begin{tabular}{|c|c|c|c|c|}
\hline Antibody & Host, type & Dilution & Source Cat., No. & Citation \\
\hline CtBP2 & Rabbit, polyclonal & $1: 1,000$ & Synaptic Systems, 193003 & Hübler et al., 2012 \\
\hline Cx36 & Mouse, monoclonal & 1:250/1:500 (slice) & Invitrogen, 37-4600 & Hilgen et al., 2011 \\
\hline Cx36 & Rabbit, polyclonal & 1:250/1:500 (slice) & Invitrogen, 36-4600 & Kihara et al., 2009 \\
\hline Cx45 & Rabbit, polyclonal & $1: 250$ & Pineda & Dedek et al., 2006 \\
\hline$D_{1}$ receptor & Mouse, monoclonal & $1: 250$ & Millipore, AB5290 & Farshi et al., 2016 \\
\hline $\mathrm{GABA}_{A}-\mathrm{R} \alpha 3$ & Rabbit, polyclonal & 1:1,000 (slice) & Sigma, G4291 & Gao et al., 1993 \\
\hline GFP & Chicken, polyclonal & $1: 500$ & Millipore, AB16901 & Saino-Saito et al., 2007 \\
\hline SCGN & Sheep, polyclonal & 1:1,000/1:1,000 (slice) & BD Biosciences, 554002 & Puthussery et al., 2011 \\
\hline Syt2 & Mouse, monoclonal & $1: 200$ & $\begin{array}{l}\text { Zebrafish International } \\
\text { Resource Center }\end{array}$ & Fox and Sanes, 2007 \\
\hline $\mathrm{TH}$ & Mouse, monoclonal & 1:500/1:1,000 (slice) & Immunostar, 22941 & Moreno et al., 2010 \\
\hline VGluT1 & Guinea pig, polyclonal & $1: 1,000$ & Millipore, AB5905 & Hilgen et al., 2011 \\
\hline
\end{tabular}

Slice, concentration used for retinal cryosections.

TABLE 2 | Statistics for Cx36-containing gap junctions on the dendrites of A8 cells and the colocalization with bipolar cell terminals.

\begin{tabular}{|c|c|c|c|c|c|c|}
\hline & Cx36 ON dendrites & Cx36 OFF dendrites & vGluT1 + Cx36 ON & VGluT1 + Cx36 OFF & SCGN + CX36 ON & SCGN + CX36 OFF \\
\hline Colocalized & $7.5 \pm 1.8$ & $9.9 \pm 2.1$ & $4.5 \pm 1$ & $4 \pm 0.5$ & $2.4 \pm 0.4$ & $1.8 \pm 0.4$ \\
\hline$\%$ & & & $57.5 \pm 12.9$ & $46.8 \pm 12$ & $28.2 \pm 3$ & $17 \pm 5.6$ \\
\hline No. of cells & 21 & 21 & 6 & 5 & 6 & 6 \\
\hline No. of mice & 15 & 15 & 5 & 4 & 5 & 5 \\
\hline
\end{tabular}

Values are given as mean \pm sd. \% refers to the amount of Cx36 puncta on A8 ON/OFF dendrites colocalized with either VGluT1 or SCGN.

mice; Figure S1). Thus, we conclude that the vast majority of A8 gap junctions are assembled from Cx36.

\section{Coupling Partners of A8 Amacrine Cells}

To test whether murine A8 cells form gap junctions only with bipolar cells (as suggested by Lee et al., 2015) or also with amacrine cells (as suggested for the cat, Kolb and Nelson, 1996), we dye-injected A8 cells in the Ier5-GFP mouse line and stained the retinal whole-mounts for Cx36 and VGluT1, which labels all bipolar cell terminals in the mouse retina (Figure 2). On both, ON (Figures 2A-C'”') and OFF dendrites of A8 cells (Figures 2E-G"'), we found Cx36-immunoreactive puncta between adjacent A8 processes and VGluT1-labeled axon terminals of bipolar cells. Similar results were obtained for vertical cryosections from Ier5-GFP mice labeled for GFP, VGluT1 and Cx36 (Figures 5A,D). Additionally, we found Cx36 puncta on injected A8 ON (Figures 2A,B,D'-D"') and OFF dendrites (Figures 2E,F,H'-H'") that were not associated with VGluT1-stained bipolar cell terminals, suggesting that these puncta represent gap junctions between A8 cells and other amacrine cells. Quantification of the colocalized puncta revealed that $\mathrm{A} 8$ cells bestow $57.5 \pm 12.9 \%$ ( $\mathrm{N}=6$ cells, from 5 mice) of their Cx36-containing gap junctions in the ON IPL and 46.8 $\pm 12 \%$ ( $\mathrm{N}=5$ cells, from 4 mice) in the OFF IPL to bipolar cells (Table 2). This suggests that roughly half of all Cx36-positive puncta on A8 amacrine cells are involved in their coupling to bipolar cells, whereas the other half presumably serves A8-toamacrine cell coupling. To discern whether these cells represent other A8 cells, as suggested for the cat retina (Kolb and Nelson, 1996), we dye-injected two adjacent A8 cells and labeled them for Cx36. The pairs of A8 cells showed enough dendritic overlap to allow assessing the presence or absence of Cx36 colocalization. As shown in Figure 3, we did not find Cx36 at contact points between the two cells, suggesting that A8 cells lack homologous coupling in the mouse retina.

Our previous results (Lee et al., 2015) showed that A8 amacrine cells likely receive glutamatergic input from any bipolar cell that stratifies in layers 1 and 4 of the IPL: type 1 and 2 OFF bipolar cells and type 6 and 7 ON bipolar cells. Thus, our next goal was to determine the types of bipolar cells A8 cells may form gap junctions with. Out of the four potential partners, only type 2 and 6 bipolar cells express the calcium-binding protein secretagogin (SCGN, Puthussery et al., 2010). We made use of this type-specific expression and stained dye-injected A8 cells (Figure 4A) and GFP-expressing A8 cells (Figure 5B) for Cx36 and SCGN in whole-mount Figures 4B-D and slice preparations, respectively. We found $\mathrm{Cx} 36$-immunoreactive puncta between A8 amacrine and SCGN-positive bipolar cell dendrites in the ON IPL (Figures 4B-D"', 5B,E). These puncta comprised $28.2 \pm 3 \%$ of all Cx36-positive structures on A8 dendrites in the ON IPL and thus $\sim 49 \%$ of the gap junctions between A 8 and ON cone bipolar cells (Table 2). Therefore, it seems reasonable to conclude that A8 cells form approximately the same number of gap junctions with SCGN-positive type 6 and SCGN-negative type 7 bipolar cells.

In contrast, Cx36-immunoreactive puncta between A8 dendrites and SCGN-positive OFF bipolar cell dendrites were 

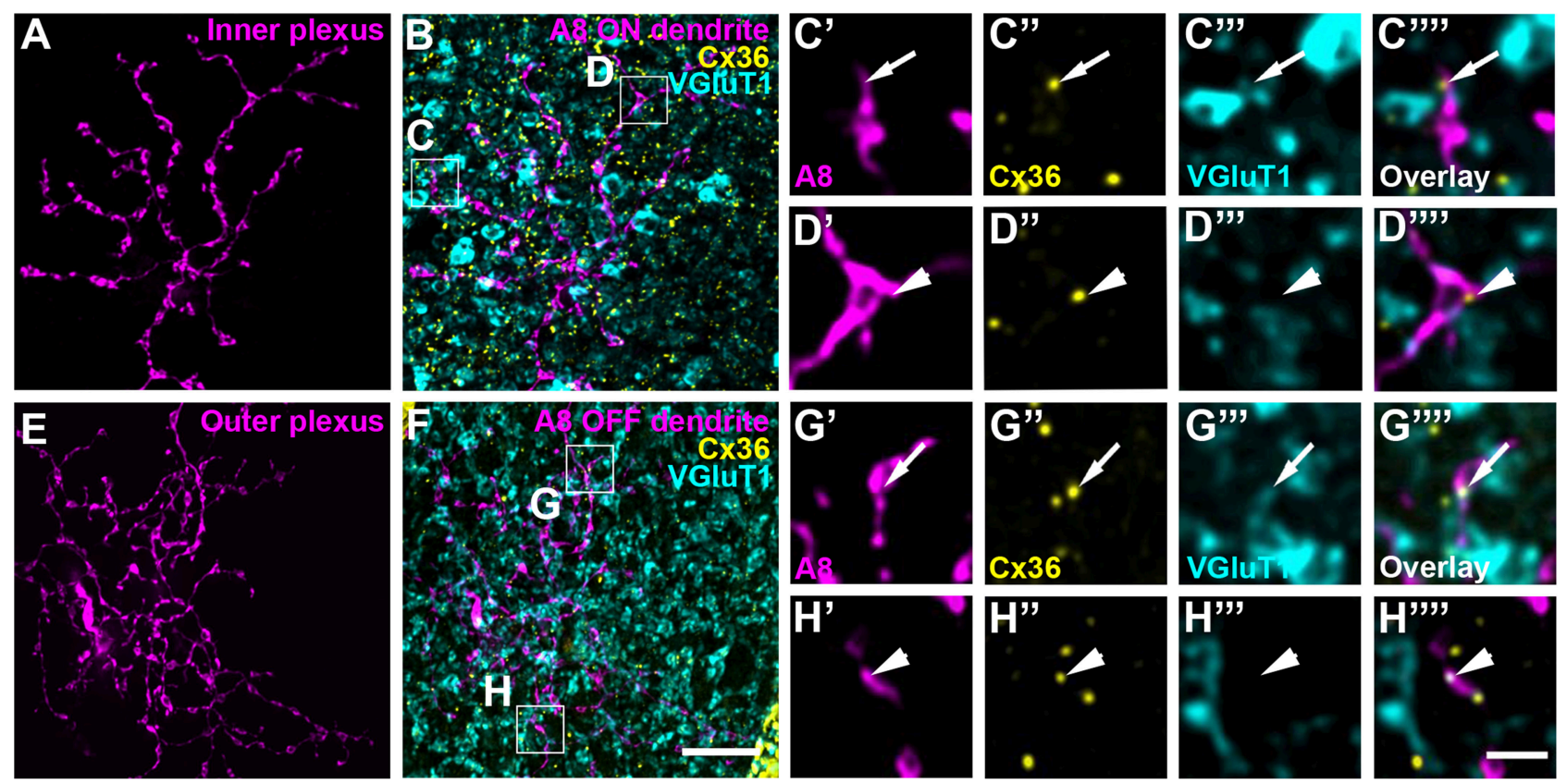

FIGURE 2 | A8 cell dendrites form Cx36-containing gap junctions with ON and OFF bipolar cell terminals. (A,E) Maximum projection of inner (A) and outer A8 dendrites (E). (B,F) Maximum projections of the overlay of Cx36 and VGluT1 with inner (B) and outer dendrites (F) of an injected A8 cell. (C'-H'') Selected areas from (B,F) as single, magnified sections: A8 dendrites (C',D',G',H'), Cx36 (C”,D”,G”,H”), VGluT1 (C'”,D”',G”',H”') and their respective overlay (C'”,D”',G”',H”') within a single section from the selected ROI. Arrows denote colocalization of all three channels (C'-C'”,'G'-G'”'). Arrowheads point to Cx36-positive puncta only colocalized with the injected A8 dendrite but not with VGluT1-positive bipolar cell terminals (D'-D'”,'H'-H'”). Scale bars: (A,B,E,F), $10 \mu \mathrm{m}$; (C'-D"'), (G'-H'”'), $2 \mu \mathrm{m}$.

found less frequently (Table 2). SCGN-positive OFF bipolar cells likely represent type 2 cells, which can also be labeled by antibodies directed against synaptotagmin-2 (Syt2). Although we again occasionally detected Cx36 between Syt2-positive bipolar cell dendrites and A8 cell dendrites (Figures 5C,F), the low degree of colocalization ( $17 \pm 5.6 \%, N=6$ cells, from 5 mice) argues against substantial coupling between type 2 OFF bipolar and A8 amacrine cells. Conversely, our data suggests that A8 cells are coupled to SCGN-negative type 1 bipolar cells in OFF IPL (Figure S2), the only other bipolar cell stratifying in sublamina 1 of the IPL.

Thus, in contrast to the non-selective glutamatergic input from bipolar cells, A8 amacrine cells seem to be more specific in their coupling pattern, with almost equal coupling to type 1 OFF bipolar cells and type 6 and 7 ON bipolar cells and weaker coupling to type 2 OFF bipolar cells. These results are in line with the tracer coupling experiments in Lee et al. (2015), which showed coupling to SCGN-positive and -negative bipolar cell somata.

\section{Input From Dopaminergic Amacrine Cells}

As gap junctions can be modulated by dopamine (Teranishi et al., 1983) and an earlier study reported input from dopaminergic amacrine cells (DACs) to A8 cells in the cat retina (Kolb et al., 1991), we labeled GFP-expressing A8 cells in the Ier5-GFP mouse line for tyrosine hydroxylase (TH), the key enzyme in dopamine synthesis. Labeling was performed in whole-mounts (Figure 6A) and vertical cryosections (Figure 6B). In retinal whole-mounts
(Figure 6A), the characteristic network of DAC dendrites became visible: many perisomatic rings were discernible, which were shown to surround the somata of AII and non-AII amacrine cells (Debertin et al., 2015). However, although the vertical section (Figures 6B,C) showed clear co-fasciculation of A8 and DAC dendrites, perisomatic rings are evidently not surrounding GFPlabeled A8 somata (Figure 6A). As DAC are also GABAergic (Contini and Raviola, 2003), we tested for GABA receptor expression at contact sites between A8 amacrine cells and DAC. Indeed, we found colocalization of all three markers in vertical sections (Figures 6D-H), suggesting that DAC may provide direct GABAergic input to A8 cells via $G_{A B A}-\alpha 3$ receptors. However, as earlier reports identified $\mathrm{GABA}_{\mathrm{A}}-\alpha 3$ receptors also on DAC (Newkirk et al., 2013), we cannot completely exclude the possibility that the GABA receptors found here are situated on the DAC side and may not represent postsynaptic receptors on A8 cells.

\section{Regulation of A8 Coupling by Dopamine?}

Dopamine affects its receptor targets ( $\mathrm{D}_{1}$ and/or $\mathrm{D}_{2}$ receptors) by volume transmission and diffusion (reviewed in Witkovsky, 2004). Consequently, a close contact between the DAC and A8 dendrites is not necessary for dopamine to influence A8 signaling. Therefore, we additionally tested for $D_{1}$ and $D_{2}$ receptor expression on dye-injected A8 cells. A8 cells did not express $\mathrm{D}_{2}$ receptors on their dendrites (Figure S3; Table S1). Whereas, the outer plexus was almost void of labeling, many $\mathrm{D}_{1}$ receptors were 

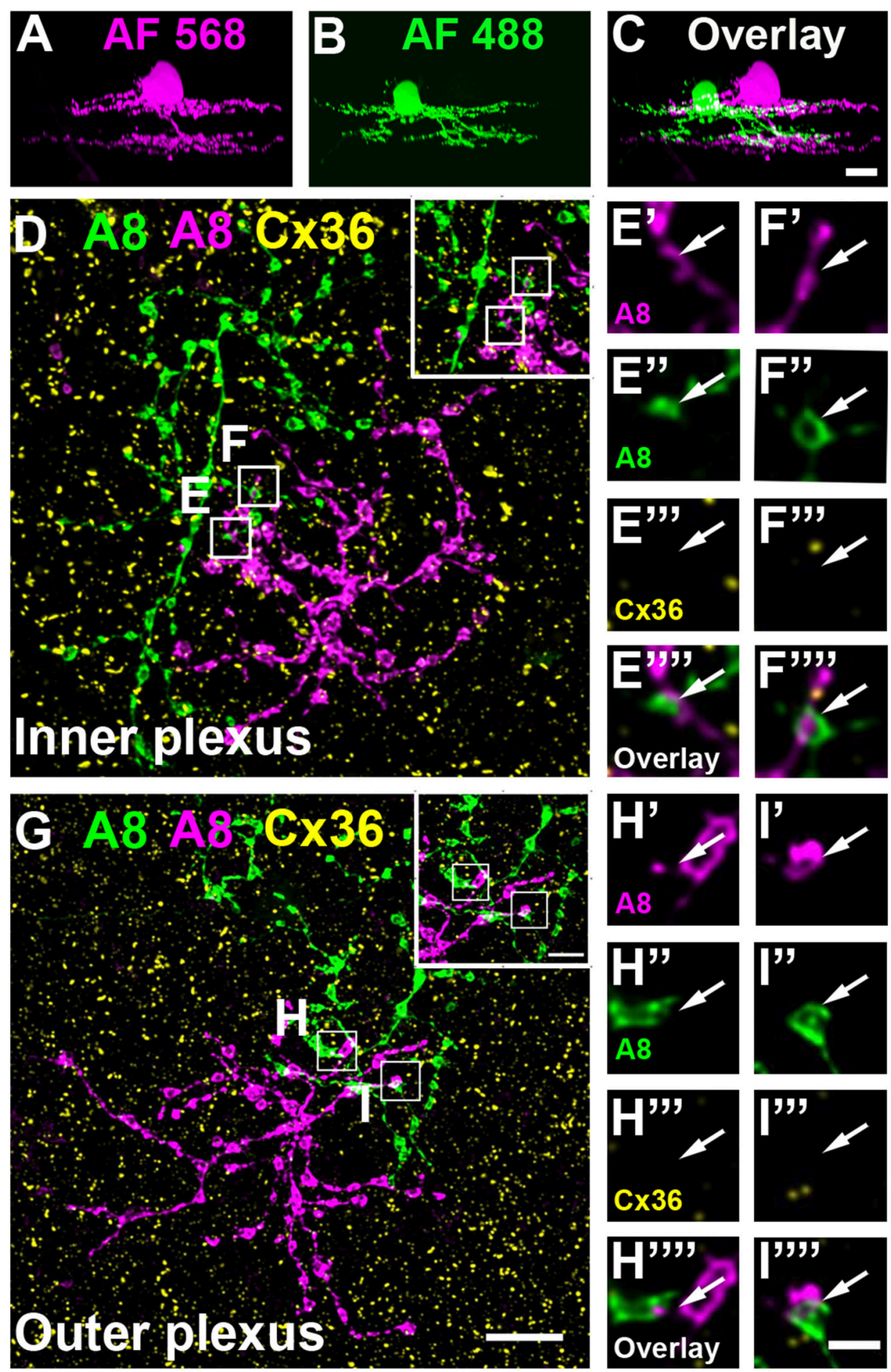

FIGURE 3 | A8 amacrine cells do not contact other A8 cells via Cx36. (A-C) XZ rotation of two A8 cells injected with Alexa Fluor 568 (A) and 488 (B) with overlapping dendrites (C). (D-I'”') Maximum projection of inner (D) and outer plexus (G) of the A8 cell pair, stained for Cx36. Insets show enlarged maximum projections of regions with A8-A8 contacts. Boxes denote the magnified regions of interest from the inner (E,F) and outer plexus (H,I) as shown in (E'-F'') and (H'-I'”'). No Cx36 labeling was detected at A8-A8 contact points (arrows). Similar results were obtained for three other A8 cell pairs. Scale bar: (A-D,G), $10 \mu \mathrm{m}$; insets in (D,G), $5 \mu \mathrm{m}$; (E'-F'"'); (H'-l'"'), $2 \mu \mathrm{m}$ 

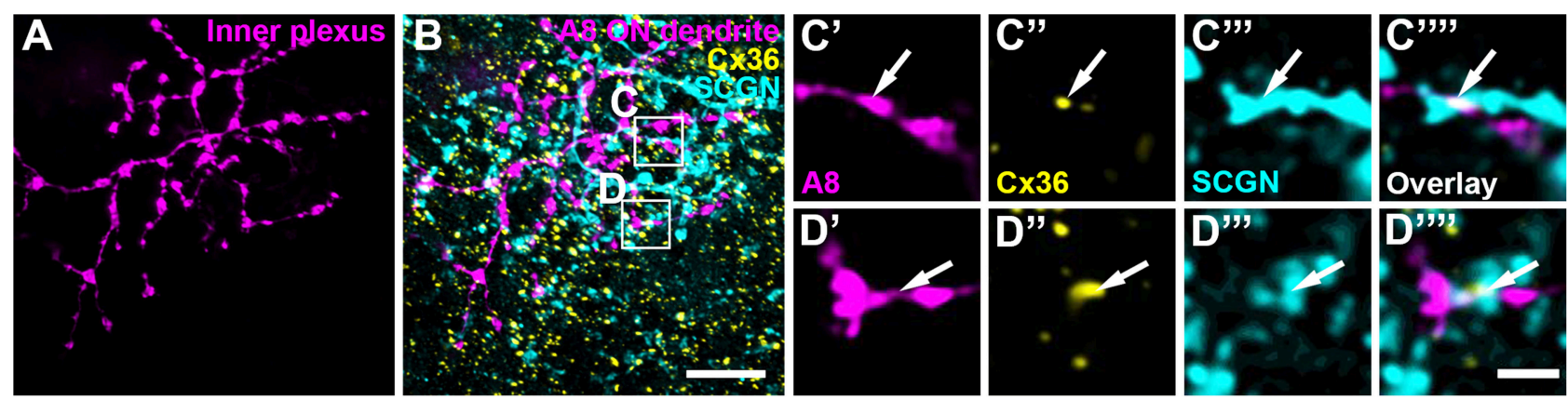

FIGURE 4 | Cx36 puncta on A8 ON dendrites colocalized with secretagogin (SCGN). (A) Maximum projection of A8 ON dendrites. (B) Maximum projection of the overlay of Cx36 and SCGN with the ON dendrites of an injected A8 cell. (C,D) Selected ROI from B. (C'-D'”') Magnified images of A8 dendrites (C',D'), Cx36 (C",D"), SCGN (C'”,D"') and their respective overlay (C'”,'D"') within a single section from the selected ROI. Arrows denote colocalization of all three channels. Scale bar: (A,B), $10 \mu \mathrm{m}$; (C'-D"'”), $2 \mu \mathrm{m}$.

found on the inner plexus of A8 cells (Figures 7A-D, $11 \pm 1 \mathrm{D}_{1^{-}}$ positive puncta per cell, $N=4$ cells, from 4 mice), suggesting that electrical coupling to $\mathrm{ON}$ cone bipolar cells may be regulated by dopamine.

To test this, we performed tracer coupling experiments in ier5-GFP mice (Figure 8). Under photopic conditions, we injected A8 amacrine cells with the gap junction-impermeable dye Alexa568 and the gap junction-permeable tracer Neurobiotin (Figures 8A-C). Retinas were preincubated (15 min) and then perfused with either control extracellular solution, the $D_{1}$ receptor antagonist Sch23390 (10 $\mu \mathrm{M}$ in extracellular solution) or the $\mathrm{D}_{1}$ receptor agonist SKF (10 $\mu \mathrm{M}$ in extracellular solution). Consistent with our earlier report (Lee et al., 2015), coupling of A8 cells to bipolar cells was weak under control conditions $(3 \pm$ 0.6 coupled cells). However, despite $\mathrm{D}_{1}$ receptor expression on A8 dendrites in the ON IPL, blocking or activating $D_{1}$ receptors did not significantly change tracer coupling (Figure 8G, $p=$ $0.5455,3.7 \pm 1.5$ coupled cells upon Sch23390 application, $N=$ 6 cells, from 4 mice; $p=0.99,2.9 \pm 1.1$ coupled cells upon SKF application, $N=7$ cells, from 5 mice). This strongly indicates that A8 coupling is not modulated by dopamine. This is surprising because A8 gap junctions are made of Cx36 which is known to be phosphorylated by a dopamine-induced signaling cascade in AII amacrine cells (Kothmann et al., 2009). However, as $\mathrm{D}_{4}$ receptor antibodies gave contradictory results (not shown), we cannot completely exclude that A8 gap junctions are modulated via $\mathrm{D}_{4}$ receptors.

To control whether our injection conditions are reliable, we also injected AII amacrine cells with and without Sch23390 in the extracellular solution (Figures 8D,E). As expected, Sch23390 significantly increased the number of bipolar cells coupled to AII cells from $14.6 \pm 0.5$ cells ( 5 cells, from 3 mice) to 18.8 \pm 1.6 cells $(5$ cells, from 4 mice; $p=0.0159$, Wilcoxon rank sum test). Additionally, Sch23390 incubation also increased the number of AII cells coupled to the injected AII (control: $5.6 \pm$ 0.7 coupled cells; Sch23390: $7 \pm 0.8$ coupled cells). However, this effect was not significant ( $p=0.175$, Wilcoxon rank sum test, $N=5$ ). Consistent with substantial expression of $D_{1}$ receptors on most but not all AII cells (Figures 7E-L"'), SKF decreased the number of coupled bipolar cells $(7.7 \pm 4.4$ coupled cells, $\mathrm{N}=6$ from 5 mice) compared to control (Figures 8D,F,G; $p=0.0089$, Wilcoxon rank sum test). Please note the AII amacrine cells, like A8 cells, did not express $\mathrm{D}_{2}$ receptors (Figure $\mathbf{S 4}$ ).

Together, these experiments revealed that Cx36-containing gap junctions are modulated by $\mathrm{D}_{1}$ receptors in one amacrine cell type (AII) but not in the other (A8) although both amacrine cells form Cx36-containing gap junctions.

\section{DISCUSSION}

In this study, we investigated the electrical synapses of A8 cells. We show that A8 gap junctions (1) are scarce and made of $\mathrm{Cx} 36$, (2) provide connections to OFF and ON bipolar cells (type 1, 2, 6, and 7; Figure 9) and another cell class, (3) are only weakly tracerpermeable under photopic conditions, and (4) are not affected by the blockade or activation of $\mathrm{D}_{1}$ dopamine receptors (despite the abundant expression of $\mathrm{D}_{1}$ receptors on $\mathrm{A} 8 \mathrm{ON}$ dendrites). Thus, although the glycinergic bistratified A8 cell makes similar connections with bipolar cells as the rod pathway-specific AII amacrine cell, the gap junctions are very different in terms of frequency and $D_{1}$ receptor-dependent regulation leaving their function enigmatic.

\section{Electrical Synapses of A8 Amacrine Cells Contain Cx36}

Electrical synapses are made of connexin proteins and the different isoforms -20 in the mouse retina-differ in their electrical and biochemical properties (Söhl and Willecke, 2003), i.e., single channel conductance, sensitivity to transjunctional voltage, $\mathrm{pH}$ etc. $\mathrm{Cx} 36$ was shown to be the most abundant connexin in the mammalian retina and other brain areas; it has a low single channel conductance ( $9 \mathrm{pS}$, Teubner et al., 2000) and can only assemble with Cx30.2 and no other connexin into heteromeric channels (Meyer et al., 2016). Gap junctions of A8 cells are made of $\mathrm{Cx} 36$ and it seems likely that $\mathrm{Cx} 36$ is also expressed by the synaptic partners (ON and OFF bipolar cells) as we always found considerable overlap between Cx36 and the respective dendrites. Whether or not Cx36 represents the connexin in the coupled non-bipolar cells, the presumed amacrine cells (see A8 amacrine cells form 

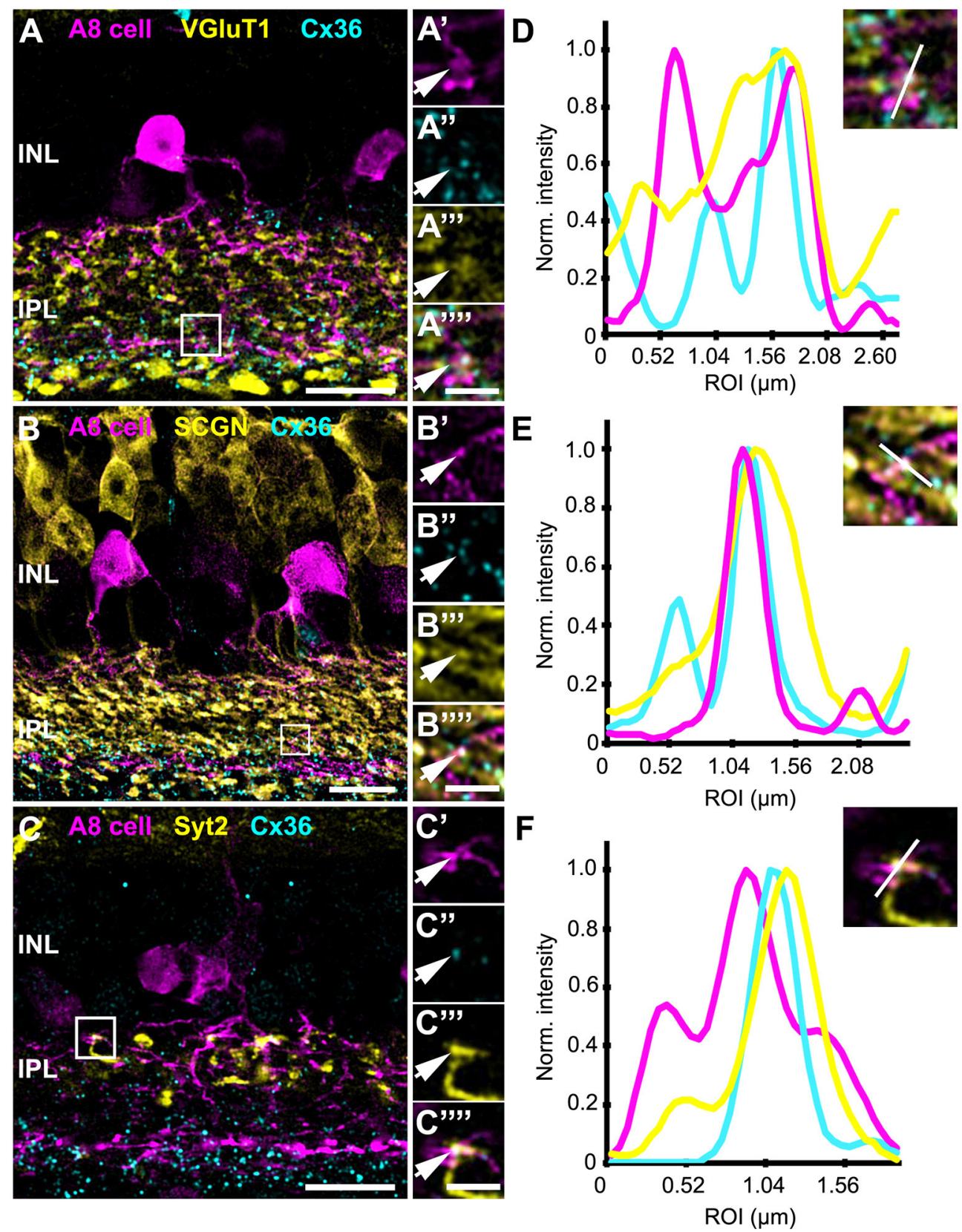

FIGURE 5 | Co-localization of A8 gap junctions with bipolar cell terminals in vertical sections. (A-C) Single retinal slices of ler5-EGFP (A8 cell) mouse stained with Cx36 and bipolar cell markers: VGluT1 (A), secretagogin [(B), SCGN], and synaptotagmin-2 [(C), Syt2]. Square white boxes in (A-C) are the selected ROls shown in (A'-C'”'). Arrows denote co-localization of all the three channels which is also represented in the normalized intensity plots (D-F). (D-F) Intensity plot for three channels, corresponding to $(\mathbf{A}-\mathbf{C})$. The respective inset represents the single scan overlay of the three channels. The plot denotes normalized pixel intensity of three channels in $y$-axis, and the $x$-axis represents the relative distance of peak intensities of the three individual channels. Scale bar: (A-C), $10 \mu \mathrm{m}$; (A'-C'”'), $2.5 \mu \mathrm{m}$.

gap junctions with bipolar and presumably amacrine cells), remains to be seen. As we also found weak overlap with $\mathrm{Cx} 45$ (Figure S1), it may also be conceivable that A8-amacrine cell coupling is heterotypic, involving $\mathrm{Cx} 36$ on the A8 side and Cx45 on the non-bipolar cell's side. A similar gap junction composition was suggested for AII and ON cone bipolar cells (Dedek et al., 2006).

\section{A8 Amacrine Cells Form Gap Junctions With Bipolar and Presumably Amacrine Cells}

To shed light on the putative function of a given neuron, it is important to study its synaptic partners. Here, we show that A8 amacrine cells form gap junctions with type 1 OFF bipolar cells and type 6 and 7 ON bipolar cells, indicating that AII and A8 

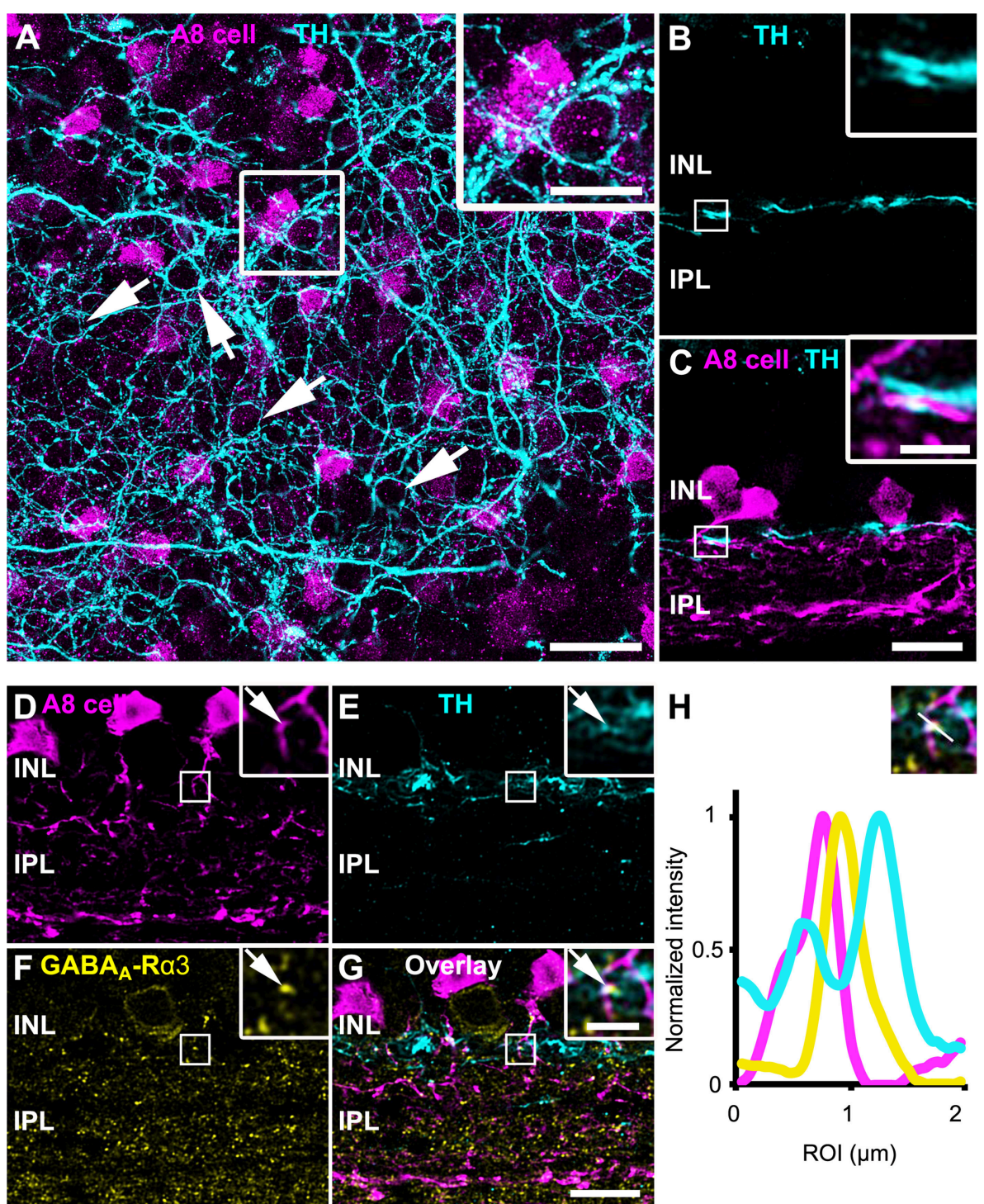

FIGURE 6 | A8 cells presumably receive GABAergic input from tyrosine hydroxylase (TH)-positive cells in the OFF IPL. (A) Maximum projection of an ler5-GFP whole-mount retina, labeled for TH (cyan). The inset shows the magnified view of the area marked in (A). Arrows point to perisomatic TH-positive rings, surrounding putative All cells (Debertin et al., 2015) but not A8 cells (magenta). (B,C) Same staining as in (A) in a single scan of a vertical slice. Please note the prominent co-fasciculation of TH- and GFP-positive dendrites of dopaminergic and A8 amacrine cells, respectively. (D-G) Maximum projection of GFP-labeled A8 cells (D), $\mathrm{TH}$-stained ier5-GFP retina (E), GABA $-\mathrm{R} \alpha 3$ staining (F) and their overlay (G). The upper inset shows the magnified view. Arrows point to the colocalization (G) of the three channels (D-F). (H) Intensity profile of the colocalized area, indicating GABAergic input from dopaminergic amacrine cells to the glycinergic A8 cell. The upper inset shows the single scan of the magnified area shown in the inset of (G). Scale bar: (A), $20 \mu \mathrm{m}$; inset: $10 \mu \mathrm{m}$; (B-G), $10 \mu \mathrm{m}$; inset, $2.5 \mu \mathrm{m}$.

amacrine cells couple to common bipolar cell types (type 6 and 7, Tsukamoto and Omi, 2017). The presence of gap junctions between A8 cells and OFF bipolar cells was surprising because earlier studies (cat: Kolb and Nelson, 1996; mouse: Lee et al., 2015) and this study did not reveal any systematic tracer coupling between A8 amacrine and OFF bipolar cells. However, in one instance we discerned an OFF bipolar cell (Syt2-negative) among the coupled bipolar cells (Figure S2), indicating that the tracer is able to spread into OFF bipolar cells. In contrast, we never saw tracer coupling to other amacrine cells in the mouse retina (Lee et al., 2015; this study), although electron microscopy suggests electrical coupling among A8 cells in the cat retina (Kolb and Nelson, 1996). One potential reason for this discrepancy may be that the dendritic tree favors tracer spread into the $\mathrm{ON}$ arbor so that $\mathrm{ON}$ cone bipolar cells become easily discernible but other coupling partners do not. Similarly, in the mouse retina, homocellular AII-AII coupling is weaker compared to heterocellular AII-ON cone bipolar cell coupling (this study; Urschel et al., 2006; Meyer et al., 2014), presumably because the stout descending dendrite favors tracer spread to ON bipolar cells. Whether the A8 gap junctions that were not colocalized with VGluT1-positive bipolar cells belong to other A8 cells, other 

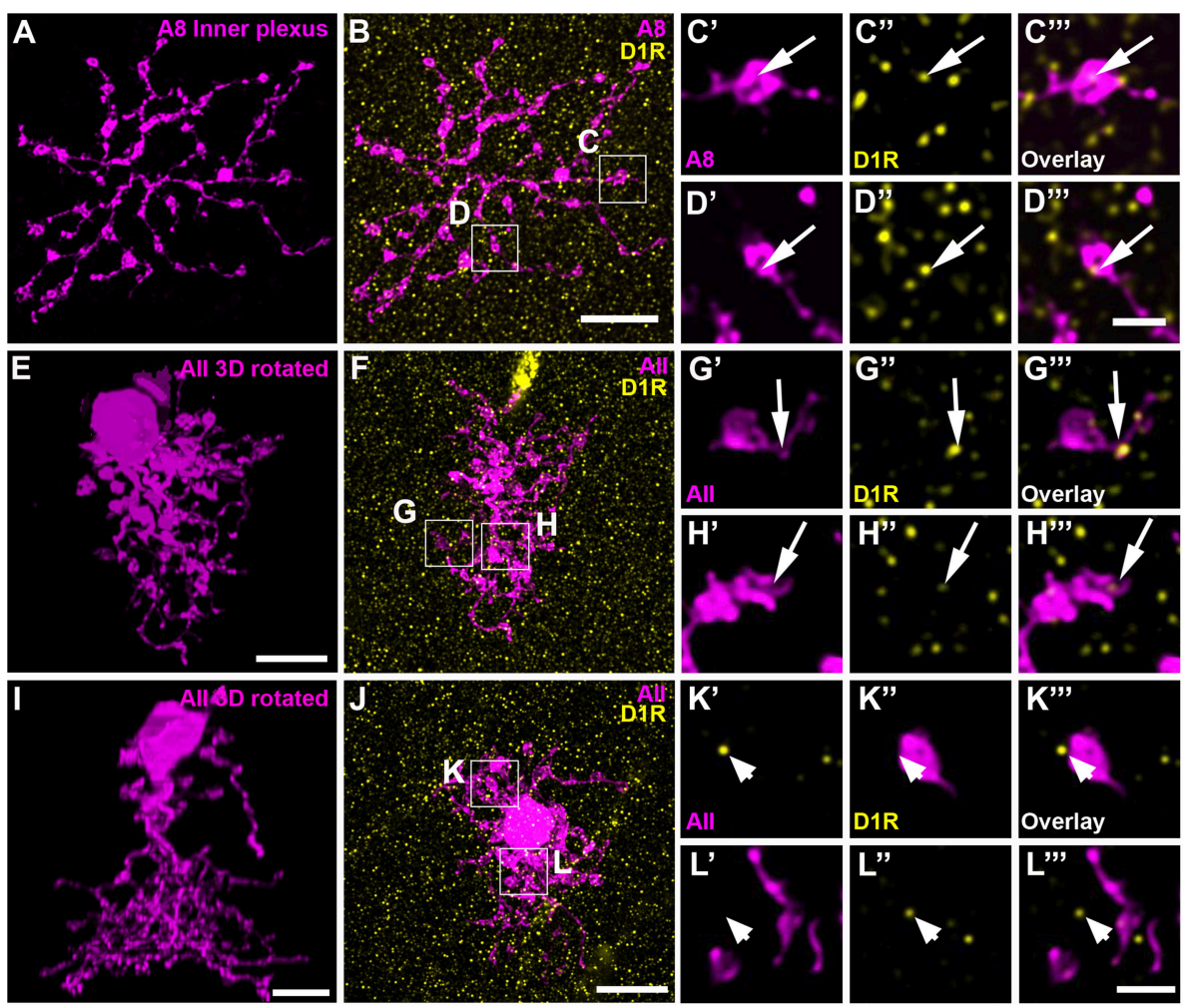

FIGURE $7 \mid D_{1}$ receptors colocalized with the $\mathrm{ON}$ dendrites of $\mathrm{A} 8$ cell and most but not all All cells. (A) Maximum projection of the inner dendrites of a dye-injected A8 cell. (B) Overlay of the A8 ON dendrites and $D_{1}$ receptors (D1R), shown as maximum projection. (C,D) Selected ROI from B. (C'-D'”') Magnified images of A8

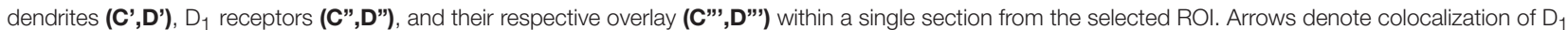
receptors with A8 ON dendrites. (E-H'") Same as (A-D"') for an injected All cell. Arrows point to $D_{1}$ receptor immunoreactivity colocalizing with All dendrites. (I-L'") Same as (E-H'”), however, this All cell did not show colocalization with $D_{1}$ receptor staining (arrowheads), consistent with a previous report on the rat retina (Veruki and Wässle, 1996). Scale bar: (A,B,E,F,I,J), $10 \mu \mathrm{m}$; (C'-D”'), (G'-H'”), (K'-L'”), $2 \mu \mathrm{m}$.
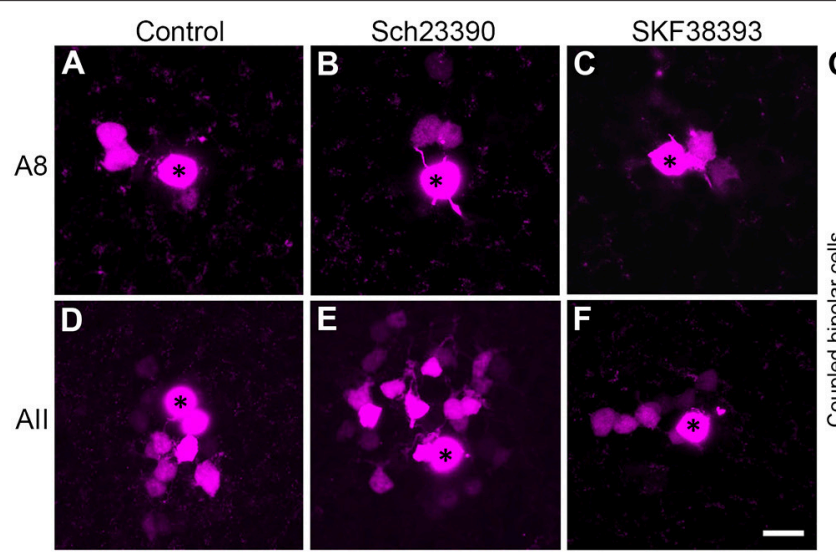

G

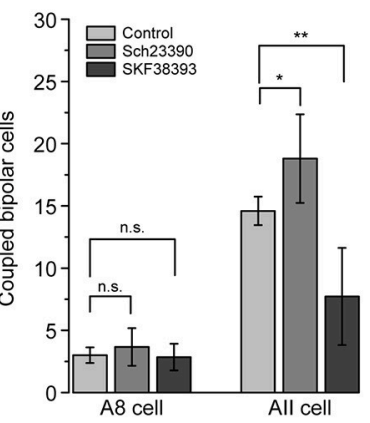

FIGURE 8 | Coupling of A8 amacrine cells did not change in the presence of the $D_{1}$ receptor antagonist Sch23390 or the $D_{1}$ receptor agonist SKF38393.

$(\mathbf{A}, \mathbf{C})$ Maximum projection of A8 (A-C) and All amacrine cell coupling (D-F) to bipolar cells in control condition $(\mathbf{A}, \mathbf{D})$ and upon application of Sch23390 (B,E) or SKF38393 (C,F). Asterisks denote the injected cells. Scale bar: (A-F), $10 \mu \mathrm{m}$. (G) Bar graph depicting the number of bipolar cells coupled to All and A8 cells. In All but not A8 amacrine cells, coupling was significantly increased in the presence of the $D_{1}$ receptor antagonist (Wilcoxon rank sum test, All cells: ${ }^{*} p=0.0159, N=5$; A8 cells: $p=0.5455, N=6$ ) and significantly decreased in the presence of the $D_{1}$ receptor agonist (Wilcoxon rank sum test, All cells: ${ }^{* *} p=0.0089, N=7$ from 5 mice; A8 cells: $p=0.99, N=7$ from 5 mice). 


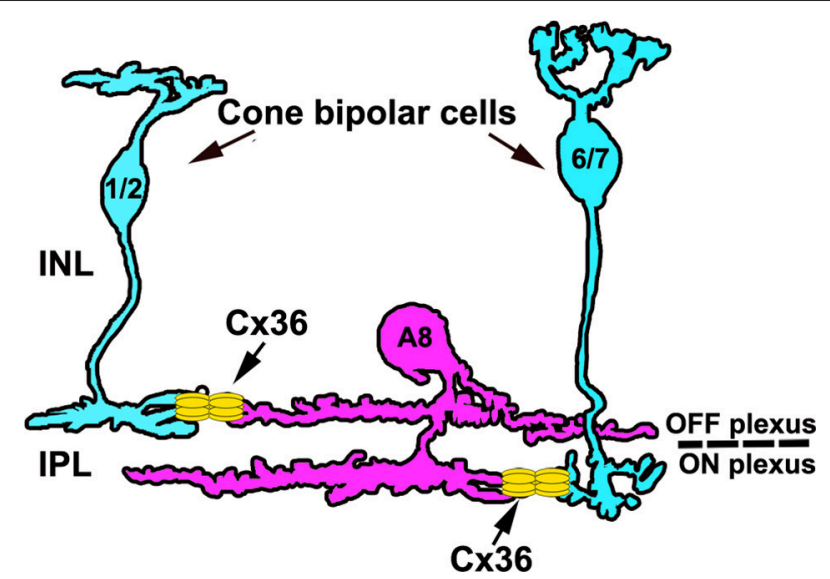

FIGURE 9 | Schematic of the electrical synapses between A8 cells and cone bipolar cells. A8 cells couple to type 1 and 2 OFF bipolar and type 6 and 7 ON bipolar cells via $\mathrm{C} \times 36$. Please note that $\mathrm{A} 8$ cell dendrites also contain $\mathrm{C} \times 36$ puncta that are not associated with bipolar cell terminals, likely representing coupling to another amacrine cell type.

amacrine or even ganglion cells could not be discerned. However, coupling to other A8 cells seems unlikely because injecting two different dyes into adjacent A8 cells with overlapping dendrites did not reveal any Cx36-positive puncta at contact pointsalthough we cannot completely rule out that a different connexin isoform mediates the coupling. Coupling to ganglion cells may also be unlikely because in their extensive studies on ganglion cells and Cx36, Pan et al. (2010) and Völgyi et al. (2009) did not describe a ganglion cell type that is tracer-coupled to a small bistratified amacrine cells. Thus, we conclude that A8 cells form heterocellular gap junctions with OFF and ON cone bipolar cells, and potentially gap junctions with other amacrine cells.

\section{Tracer Coupling of A8 Amacrine Cells Was Not Modulated by $D_{1}$ Receptors}

In recent years, evidence accumulated that gap junctions are not static but highly dynamic multi-protein complexes (reviewed in O'Brien, 2014). The neuromodulator dopamine, for example, was shown to directly influence gap junction permeability in different retinal neurons (amacrines: Hampson et al., 1992; Mills and Massey, 1995; horizontal cells: He et al., 2000). Interestingly, the Cx36-containing gap junctions of AII cells in the rabbit retina were shown to be differentially regulated: The heterocellular AIION cone bipolar cell gap junctions are regulated by cGMPdependent pathways (Mills and Massey, 1995); the homocellular AII-AII gap junctions, in contrast, are closed by dopamine (Mills and Massey, 1995), via an intracellular signaling cascade leading to PP2A-mediated dephosphorylation of Cx36 (Kothmann et al., 2009). Our data show that blocking the $D_{1}$ dopamine receptors of AII cells with Sch23390 increases the coupling to ON cone bipolar cells, consistent with a previous study on mouse retina (Urschel et al., 2006). However, this may partially represent a secondary effect because the gap junction-permeable tracer spread slightly stronger within the AII network and presumably from there to more ON cone bipolar cells (Figures $\mathbf{8 D}, \mathbf{E}, \mathbf{G}$ ).
Moreover, activation of $D_{1}$ receptors by SKF decreased ON cone bipolar /AII cell coupling. In contrast, Sch23390 and SKF did not affect A8 coupling. The reason may be the rather low number of gap junction plaques mediating A8-ON cone bipolar cell and A8-amacrine cell coupling. Secondary dye spread is probably minimal, preventing an increase in coupling when $\mathrm{D}_{1}$ receptors are blocked. Thus, the numerous $\mathrm{D}_{1}$ receptors on A8 cell ON dendrites, which do not colocalize with $\mathrm{Cx} 36$ (Figure S5), likely affect chemical instead of electrical synapses on A8 cells. Indeed, previous work suggests that $\mathrm{D}_{1}$ receptors may cause changes in amacrine cell-mediated inhibition in the mouse retina (Flood et al., 2018). Please note that our study may not exclude the possibility that A8 coupling is modulated via other dopamine receptors (e.g., $\mathrm{D}_{4}$ ) or that it is modulated by NO/cGMP, as shown for ON cone bipolar/AII coupling (Mills and Massey, 1995).

\section{Functional Implications and Comparison With All Amacrine Cells}

A8 amacrine and AII amacrine cells share many features: (a) They are both small-field amacrine cells and consequently are densely distributed across the retina (Helmstaedter et al., 2013). (b) Both cells are bistratified and make connections with $\mathrm{ON}$ and OFF bipolar cells. (c) AII and A8 cells are glycinergic, providing crossover inhibition (Werblin, 2010) to OFF bipolar and ganglion cells. However, whereas AII cells inhibit OFF- $\alpha$ ganglion cells (mouse: van Wyk et al., 2009), A8 cells provide glycinergic input to ON- $\alpha$ ganglion cells (Lee et al., 2015). (d) Both cells form electrical synapses with bipolar cells but gap junctions of A8 cells differ from that of AII cells in three major respects: (1) A8 gap junctions are less numerous $(<20$ per cell) compared to AII gap junctions which were shown to form $\sim 150$ per cell (Meyer et al., 2014), although a recent electron microscopy study demonstrated less gap junctions per AII cell ( $\sim 50$, Tsukamoto and Omi, 2017). As both cells are also coupled to non-bipolar cells, it is necessary to compare the number of gap junctions to bipolar cells between the two cell types. Of the $\sim 17$ gap junctions an A8 cell is forming, it employs $\sim 8$ to couple with bipolar cells. In comparison, AII amacrine cells were shown to use 25-30 gap junctions for coupling with ON cone bipolar cells (Meyer et al., 2014; Tsukamoto and Omi, 2017). Both cell types couple to type 6 and 7 ON bipolar cells, but data from electron microscopy suggests that coupling to AII cells (Tsukamoto and Omi, 2017) is much stronger than to A8 cells for a given type 6 or 7 cell. 2) A8 cells also form gap junctions with OFF bipolar cells whereas AII cells only contact ON cone bipolar cells via electrical synapses (Veruki and Hartveit, 2002; Tsukamoto and Omi, 2017). This suggests that A8 cells make gap junctions with the same cells they receive glutamatergic input from, indicating that gap junctions may serve to facilitate cone bipolar cell signaling. Excitation from bipolar cells presumably reaches the A8 dendrite first via the electrical synapse, slightly depolarizing the A8 dendrite. The subsequent glutamatergic input could then be enhanced (Kolb and Nelson, 1996; Lee et al., 2015). This speculation would be bolstered by the presence of mixed synapses at A8 cells. However, we did not find any colocalization for 
ribbon and electrical synapses on A8 cell dendrites, despite the considerable overlap of Cx36 with CtBP2-labeled ribbons in the ON sublamina of the IPL (Table S2). The majority of these mixed synapses potentially belongs to AII cells as virtually every class of ON cone bipolar cells couples to AII cells (Tsukamoto and Omi, 2017), including SCGN-positive and -negative bipolar cells (Figure S6). (3) Electrical coupling is much weaker with only 34 coupled bipolar cells in A8 cells under photopic conditions, in contrast to AII cells which are tracer-coupled to $\sim 15$ bipolar cells when injected under the same conditions. (4) Finally, A8 coupling is not modulated by dopamine but potentially, other intracellular signaling cascades may affect A8 coupling. However, given the low amount of $\mathrm{Cx} 36$ immunoreactivity on $\mathrm{A} 8$ dendrites (Table 2), it seems unlikely that coupling will be strong under any light condition or activity-dependent modulation.

In summary, although A8 and AII cells share many properties, they presumably fulfill very different functions. Initially, we hypothesized that A8 cells may support AII cells in mediating rod-derived signals into the cone pathways (Güldenagel et al., 2001; Deans et al., 2002) because they may receive signals from rod bipolar cells indirectly via AII cells and ON cone bipolar cells. However, given the low degree of electrical coupling to ON cone bipolar cells, this scenario seems unlikely now. Interestingly, we found that A8 cells may provide glycinergic inhibition to the OFF dendrites of AII cells (data not shown), opening up the possibility that A8 cells directly influence the AII pathways. Collectively, our study may form the basis for further analyses elucidating the function of A8 cells in retinal processing.

\section{ETHICS STATEMENT}

All procedures and experiments conducted in this study complied with the guidelines of the European Communities

\section{REFERENCES}

Bloomfield, S. A., and Völgyi, B. (2004). Function and plasticity of homologous coupling between AII amacrine cells. Vision Res. 44, 3297-3306. doi: 10.1016/j.visres.2004.07.012

Chen, X., Hsueh, H. A., and Werblin, F. S. (2011). Amacrine-toamacrine cell inhibition: spatiotemporal properties of GABA and glycine pathways. Vis. Neurosci. 28, 193-204. doi: 10.1017/S09525238 11000137

Contini, M., and Raviola, E. (2003). GABAergic synapses made by a retinal dopaminergic neuron. Proc. Natl. Acad. Sci. U.S.A. 100, 1358-1363. doi: $10.1073 /$ pnas. 0337681100

Deans, M. R., Volgyi, B., Goodenough, D. A., Bloomfield, S. A., and Paul, D. L. (2002). Connexin36 is essential for transmission of rodmediated visual signals in the mammalian retina. Neuron 36, 703-712. doi: 10.1016/S0896-6273(02)01046-2

Debertin, G., Kántor, O., Kovács-Öller, T., Balogh, L., Szabó-Meleg, E., Orbán, J., et al. (2015). Tyrosine hydroxylase positive perisomatic rings are formed around various amacrine cell types in the mammalian retina. J. Neurochem. 134, 416-428. doi: 10.1111/jnc.13144

Dedek, K., Schultz, K., Pieper, M., Dirks, P., Maxeiner, S., Willecke, K., et al. (2006). Localization of heterotypic gap junctions composed of connexin45 and connexin36 in the rod pathway of the mouse retina. Eur. J. Neurosci. 24, 1675-1686. doi: 10.1111/j.1460-9568.2006.05 052.x
Council Directive (86/609/EEC) and the laws of the Federal Government of Germany (Tierschutzgesetz; BGBl. I S. 1206, 1313 and BGBl. I S. 1934) for experimental animals and were approved by the local animal care committee (Niedersaechsisches Landesamt fuer Verbraucherschutz und Lebensmittelsicherheit).

\section{AUTHOR CONTRIBUTIONS}

KD, ST, and SY designed experiments. ST and SY performed experiments. All authors contributed to the interpretation of data. KD wrote the manuscript with help from SY. ST and SY prepared all figures which were finalized by KD. All authors edited and commented on the manuscript and KD finalized it.

\section{FUNDING}

This work was supported by the DFG (DE1154/5-1 to KD) and the European Union's Horizon 2020 research and innovation programme under the Marie Skłodowska-Curie grant agreement No 674901 (to KD).

\section{ACKNOWLEDGMENTS}

We thank Bettina Kewitz for excellent technical assistance. We are also grateful to Dr. Silke Haverkamp (caesar, Bonn, Germany) and Dr. Botond Roska (FMI, Basel, Switzerland) for providing the Ier5-GFP mice.

\section{SUPPLEMENTARY MATERIAL}

The Supplementary Material for this article can be found online at: https://www.frontiersin.org/articles/10.3389/fnmol. 2019.00099/full\#supplementary-material

Farshi, P., Fyk-Kolodziej, B., Krolewski, D. M., Walker, P. D., and Ichinose, T. (2016). Dopamine D1 receptor expression is bipolar cell type-specific in the mouse retina. J. Comp. Neurol. 524, 2059-2079. doi: 10.1002/cne.23932

Feigenspan, A., Teubner, B., Willecke, K., and Weiler, R. (2001). Expression of neuronal connexin36 in AII amacrine cells of the mammalian retina. J. Neurosci. 21, 230-239. doi: 10.1523/JNEUROSCI.21-01-00230.2001

Flood, M. D., Moore-Dotson, J. M., and Eggers, E. D. (2018). Dopamine D1 receptor activation contributes to light-adapted changes in retinal inhibition to rod bipolar cells. J. Neurophysiol. 120, 867-879. doi: 10.1152/jn.00855.2017

Fox, M. A., and Sanes, J. R. (2007). Synaptotagmin I and II are present in distinct subsets of central synapses. J. Comp. Neurol. 503, 280-296. doi: 10.1002/cne.21381

Gao, B., Fritschy, J. M., Benke, D., and Mohler, H. (1993). Neuron-specific expression of GABAA-receptor subtypes: differential association of the alpha 1and alpha 3-subunits with serotonergic and GABAergic neurons. Neuroscience 54, 881-892. doi: 10.1016/0306-4522(93)90582-Z

Güldenagel, M., Ammermüller, J., Feigenspan, A., Teubner, B., Degen, J., Söhl, G., et al. (2001). Visual transmission deficits in mice with targeted disruption of the gap junction gene connexin36. J. Neurosci. 21, 6036-6044. doi: 10.1523/JNEUROSCI.21-16-06036.2001

Hampson, E. C., Vaney, D. I., and Weiler, R. (1992). Dopaminergic modulation of gap junction permeability between amacrine cells in mammalian retina. J. Neurosci. 12, 4911-4922. doi: 10.1523/JNEUROSCI.12-12-04911.1992

He, S., Weiler, R., and Vaney, D. I. (2000). Endogenous dopaminergic regulation of horizontal cell coupling in the mammalian retina. J. Comp. 
Neurol. 418, 33-40. doi: 10.1002/(SICI)1096-9861(20000228)418:1\&lt;33::AIDCNE3\&gt;3.0.CO;2-J

Helmstaedter, M., Briggman, K. L., Turaga, S. C., Jain, V., Seung, H. S., and Denk, W. (2013). Connectomic reconstruction of the inner plexiform layer in the mouse retina. Nature 500, 168-174. doi: 10.1038/nature12346

Hilgen, G., von Maltzahn, J., Willecke, K., Weiler, R., and Dedek, K. (2011). Subcellular distribution of connexin 45 in OFF bipolar cells of the mouse retina. J. Comp. Neurol. 519, 433-450. doi: 10.1002/cne.22526

Hübler, D., Rankovic, M., Richter, K., Lazarevic, V., Altrock, W. D., Fischer, K.-D., et al. (2012). Differential spatial expression and subcellular localization of CtBP family members in rodent brain. PLoS ONE 7:e39710. doi: 10.1371 /journal.pone. 0039710

Kántor, O., Varga, A., Nitschke, R., Naumann, A., Énzsöly, A., Lukáts, Á., et al. (2017). Bipolar cell gap junctions serve major signaling pathways in the human retina. Brain Struct. Funct. 222, 2603-2624. doi: 10.1007/s00429-016-1360-4

Kihara, A. H., Paschon, V., Cardoso, C. M., Higa, G. S. V., Castro, L. M., Hamassaki, D. E., et al. (2009). Connexin36, an essential element in the rod pathway, is highly expressed in the essentially rodless retina of Gallus gallus. J. Comp. Neurol. 512, 651-663. doi: 10.1002/cne.21920

Kolb, H., Cuenca, N., and Dekorver, L. (1991). Postembedding immunocytochemistry for GABA and glycine reveals the synaptic relationships of the dopaminergic amacrine cell of the cat retina. J. Comp. Neurol. 310, 267-284. doi: 10.1002/cne.903100210

Kolb, H., and Nelson, R. (1996). Hyperpolarizing, small-field, amacrine cells in cone pathways of cat retina. J. Comp. Neurol. 371, 415-436. doi: 10.1002/(SICI)1096-9861(19960729)371:3\&lt;415::AIDCNE5\&gt;3.0.CO;2-5

Kolb, H., Nelson, R., and Mariani, A. (1981). Amacrine cells, bipolar cells and ganglion cells of the cat retina: a Golgi study. Vision Res. 21, 1081-1114. doi: 10.1016/0042-6989(81)90013-4

Kothmann, W. W., Massey, S. C., and O'Brien, J. (2009). Dopamine-stimulated dephosphorylation of connexin 36 mediates AII amacrine cell uncoupling. $J$. Neurosci. 29, 14903-14911. doi: 10.1523/JNEUROSCI.3436-09.2009

Lee, S. C. S., Meyer, A., Schubert, T., Hüser, L., Dedek, K., and Haverkamp, S. (2015). Morphology and connectivity of the small bistratified A8 amacrine cell in the mouse retina. J. Comp. Neurol. 523, 1529-1547. doi: 10.1002/ cne. 23752

Li, X., Kamasawa, N., Ciolofan, C., Olson, C. O., Lu, S., Davidson, K. G. V., et al. (2008). Connexin45-containing neuronal gap junctions in rodent retina also contain Connexin36 in both apposing hemiplaques, forming bihomotypic gap junctions, with scaffolding contributed by zonula occludens-1. J. Neurosci. 28, 9769-9789. doi: 10.1523/JNEUROSCI.213708.2008

Marc, R. E., Anderson, J. R., Jones, B. W., Sigulinsky, C. L., and Lauritzen, J. S. (2014). The AII amacrine cell connectome: a dense network hub. Front. Neural Circuits 8:104. doi: 10.3389/fncir.2014.00104

Maxeiner, S., Dedek, K., Janssen-Bienhold, U., Ammermüller, J., Brune, H., Kirsch, T., et al. (2005). Deletion of connexin 45 in mouse retinal neurons disrupts the rod/cone signaling pathway between AII amacrine and ON cone bipolar cells and leads to impaired visual transmission. J. Neurosci. 25, 566-576. doi: 10.1523/JNEUROSCI.3232-04.2005

Menger, N., Pow, D. V., and Wässle, H. (1998). Glycinergic amacrine cells of the rat retina. J. Comp. Neurol. 401, 34-46. doi: 10.1002/(SICI)1096-9861(19981109)401:1\&lt;34::AIDCNE3\&gt;3.0.CO;2-P

Meyer, A., Hilgen, G., Dorgau, B., Sammler, E. M., Weiler, R., Monyer, H., et al. (2014). AII amacrine cells discriminate between heterocellular and homocellular locations when assembling connexin36-containing gap junctions. J. Cell. Sci. 127, 1190-1202. doi: 10.1242/jcs. 133066

Meyer, A., Tetenborg, S., Greb, H., Segelken, J., Dorgau, B., Weiler, R., et al. (2016). Connexin30.2: in vitro interaction with Connexin36 in HeLa cells and expression in AII amacrine cells and intrinsically photosensitive ganglion cells in the mouse retina. Front. Mol. Neurosci. 9:36. doi: 10.3389/fnmol.2016. 00036

Meyer, A., Yadav, S. C., and Dedek, K. (2018). Phenotyping of gapjunctional coupling in the mouse retina. Methods Mol. Biol. 1753, 249-259. doi: 10.1007/978-1-4939-7720-8_17
Mills, S. L., and Massey, S. C. (1995). Differential properties of two gap junctional pathways made by AII amacrine cells. Nature 377, 734-737. doi: $10.1038 / 377734 \mathrm{a} 0$

Moreno, N., Morona, R., López, J. M., and González, A. (2010). Subdivisions of the turtle Pseudemys scripta subpallium based on the expression of regulatory genes and neuronal markers. J. Comp. Neurol. 518, 4877-4902. doi: $10.1002 /$ cne.22493

Newkirk, G. S., Hoon, M., Wong, R. O., and Detwiler, P. B. (2013). Inhibitory inputs tune the light response properties of dopaminergic amacrine cells in mouse retina. J. Neurophysiol. 110, 536-552. doi: 10.1152/jn.00118.2013

O'Brien, J. (2014). The ever-changing electrical synapse. Curr. Opin. Neurobiol. 29, 64-72. doi: 10.1016/j.conb.2014.05.011

Pan, F., Paul, D. L., Bloomfield, S. A., and Völgyi, B. (2010). Connexin36 is required for gap junctional coupling of most ganglion cell subtypes in the mouse retina. J. Comp. Neurol. 518, 911-927. doi: 10.1002/cne.22254

Puthussery, T., Gayet-Primo, J., and Taylor, W. R. (2010). Localization of the calcium-binding protein secretagogin in cone bipolar cells of the mammalian retina. J. Comp. Neurol. 518, 513-525. doi: 10.1002/cne.22234

Puthussery, T., Gayet-Primo, J., Taylor, W. R., and Haverkamp, S. (2011). Immunohistochemical identification and synaptic inputs to the diffuse bipolar cell type DB1 in macaque retina. J. Comp. Neurol. 519, 3640-3656. doi: $10.1002 /$ cne.22756

Saino-Saito, S., Cave, J. W., Akiba, Y., Sasaki, H., Goto, K., Kobayashi, K., et al. (2007). ER81 and CaMKIV identify anatomically and phenotypically defined subsets of mouse olfactory bulb interneurons. J. Comp. Neurol. 502, 485-496. doi: $10.1002 /$ cne. 21293

Schindelin, J., Arganda-Carreras, I., Frise, E., Kaynig, V., Longair, M., Pietzsch, T., et al. (2012). Fiji: an open-source platform for biological-image analysis. Nat. Methods 9, 676-682. doi: 10.1038/nmeth.2019

Siegert, S., Scherf, B. G., Del Punta, K., Didkovsky, N., Heintz, N., and Roska, B. (2009). Genetic address book for retinal cell types. Nat. Neurosci. 12, 1197-1204. doi: 10.1038/nn.2370

Söhl, G., and Willecke, K. (2003). An update on connexin genes and their nomenclature in mouse and man. Cell Commun. Adhes. 10, 173-180. doi: 10.1080/cac.10.4-6.173.180

Teranishi, T., Negishi, K., and Kato, S. (1983). Dopamine modulates S-potential amplitude and dye-coupling between external horizontal cells in carp retina. Nature 301, 243-246. doi: 10.1038/301243a0

Tetenborg, S., Yadav, S. C., Hormuzdi, S. G., Monyer, H., Janssen-Bienhold, U., and Dedek, K. (2017). Differential distribution of retinal Ca2+/CalmodulinDependent Kinase II (CaMKII) isoforms indicates CaMKII- $\beta$ and $-\delta$ as specific elements of electrical synapses made of Connexin36 (Cx36). Front. Mol. Neurosci. 10:425. doi: 10.3389/fnmol.2017.00425

Teubner, B., Degen, J., Söhl, G., Güldenagel, M., Bukauskas, F. F., Trexler, E. B., et al. (2000). Functional expression of the murine connexin 36 gene coding for a neuron-specific gap junctional protein. J. Membr. Biol. 176, 249-262. doi: 10.1007/s00232001094

Tsukamoto, Y., and Omi, N. (2013). Functional allocation of synaptic contacts in microcircuits from rods via rod bipolar to AII amacrine cells in the mouse retina. J. Comp. Neurol. 521, 3541-3555. doi: 10.1002/ cne. 23370

Tsukamoto, Y., and Omi, N. (2017). Classification of mouse retinal bipolar cells: type-specific connectivity with special reference to rod-driven AII amacrine pathways. Front. Neuroanat. 11:92. doi: 10.3389/fnana.2017.00092

Urschel, S., Höher, T., Schubert, T., Alev, C., Söhl, G., Wörsdörfer, P., et al. (2006). Protein kinase A-mediated phosphorylation of connexin 36 in mouse retina results in decreased gap junctional communication between AII amacrine cells. J. Biol. Chem. 281, 33163-33171. doi: 10.1074/jbc.M606396200

van Wyk, M., Wässle, H., and Taylor, W. R. (2009). Receptive field properties of ON- and OFF-ganglion cells in the mouse retina. Vis. Neurosci. 26, 297-308. doi: $10.1017 /$ S0952523809990137

Veruki, M. L., and Hartveit, E. (2002). Electrical synapses mediate signal transmission in the rod pathway of the mammalian retina. J. Neurosci. 22, 10558-10566. doi: 10.1523/JNEUROSCI.22-24-10558.2002

Veruki, M. L., and Wässle, H. (1996). Immunohistochemical localization of dopamine D1 receptors in rat retina. Eur. J. Neurosci. 8, 2286-2297. doi: $10.1111 /$ j.1460-9568.1996.tb01192.x 
Völgyi, B., Chheda, S., and Bloomfield, S. A. (2009). Tracer coupling patterns of the ganglion cell subtypes in the mouse retina. J. Comp. Neurol. 512, 664-687. doi: $10.1002 /$ cne. 21912

Werblin, F. S. (2010). Six different roles for crossover inhibition in the retina: correcting the nonlinearities of synaptic transmission. Vis. Neurosci. 27, 1-8. doi: 10.1017/S0952523810000076

Werblin, F. S. (2011). The retinal hypercircuit: a repeating synaptic interactive motif underlying visual function. J. Physiol. 589, 3691-3702. doi: 10.1113/jphysiol.2011.210617

Witkovsky, P. (2004). Dopamine and retinal function. Doc. Ophthalmol. 108, 17-40. doi: 10.1023/B:DOOP.0000019487.88486.0a
Conflict of Interest Statement: The authors declare that the research was conducted in the absence of any commercial or financial relationships that could be construed as a potential conflict of interest.

Copyright (c) 2019 Yadav, Tetenborg and Dedek. This is an open-access article distributed under the terms of the Creative Commons Attribution License (CC BY). The use, distribution or reproduction in other forums is permitted, provided the original author(s) and the copyright owner(s) are credited and that the original publication in this journal is cited, in accordance with accepted academic practice. No use, distribution or reproduction is permitted which does not comply with these terms. 